\title{
EDITORIAL
}

\section{EFFECTIVE CLINICAL PRACTICE FOR OLDER PEOPLE WITH TYPE 2 DIABETES. GLUCOSE REGULATION IS IMPORTANT BUT OTHER STRATEGIES ALSO NEED TO BE INCLUDED}

\author{
G. PAOLISSO ${ }^{1}$, A.J. SINCLAIR ${ }^{2}$
}

1. Professor of Medicine, Department of Geriatric Medicine and Metabolic Diseases, Second University of Naples, Naples, Italy, Email: giuseppe.paolisso@ unina2.it; 2. Professor of Medicine, Bedfordshire \& Hertfordshire Postgraduate Medical School, Putteridge Bury campus, University of Bedfordshire, Luton, LU2 8LE, UK, Tel : 00 44 (0) 1582 743285, Fax : 0044 (0) 1582 743286, Email : alan.sinclair@beds.ac.uk

A modern healthcare system that delivers high quality diabetes care for older people requires integrated care between primary and community diabetes care professionals, hospital specialists (diabetologists and geriatricians) and other members of the health care team. This should have a multi-dimensional approach with an emphasis on prevention of diabetes and its complications, and early intervention strategies for vascular disease. There has also been a recent emphasis on the comprehensive assessment of disability due to lower limb dysfunction, eye disease and stroke with a consequent need to promote well-being and a normal life expectancy. This poses great challenges on health professionals in terms of their capacity and the acquisition of skill sets to deliver meaningful outcome targets. This is exacerbated by a growing prevalence of diabetes worldwide and the additional need for primary and secondary prevention of diabetes.

In light of such epidemiologic evidence and expressed clinical need, Bourdel-Marchasson and colleagues (1) are right to focus on an important area of unresolved consensus in the management of diabetes in older people - the management of glucose control. Despite a large number of publications in adult diabetes, only few data have been reported in old or very old diabetic patients. This suggests a lack of recognition that substantial age-related physiological changes occurring in tissue and organs and the potential occurrence of frailty could make inapplicable metabolic targets highlighted for younger adults with diabetes. The approach taken by the authors is to provide a comprehensive account of all relevant available evidence and offer practical elements in assisting clinical management decisions. They criticise the existing lack of metabolic targets for older people given by international guidelines of diabetes and the failure to allow for frailty and its consequences.

These criticisms may to an extent be justified and some might suggest that it reflects health inequality in diabetes care for older people. This may also be manifested as a lack of access to services, inaquedate specialist provision, poorer clinical outcomes and patients and family dissatisfaction. However, it is for these reasons outlined above that the European Diabetes Working Party for Older People (EDWPOP) have completed a detailed evidenced-based review of all relevant literature, Clinical Guidelines for Older People with Type 2 Diabetes Mellitus, which is available online: (www.instituteofdiabetes.org). The EDWPOP identified various primary areas of concerns and produced a series of target areas for concerted actions. There were based on common but important clinical issues relevant to most people with diabetes, but, in addition, other areas were identified which were deemed to satisfy a series of additional criteria: each has a significant impact on the lives of older people with diabetes and their families. In each case some supporting evidence was available but careful scrutiny by an experienced review group was necessary to derive an appropriate grade of discussion and recommendation. The lack of sufficient clinical evidence base for establishing recommendations on best practice was recognized and highlighted by the absence of any large scale intervention studies in older people with 2 diabetes, no substantial benefit for glucose or lipid lowering, no evidence of large studies on in diabetics resident of care homes, and no evidence to recommend a particular care model. The guidance has been presented widely in Europe, the United States, Central America and in several other countries.

In relation to metabolic targets, a recent revision of the EDWPOP guidance due for publication later in 2009 (Executive Summary) recommends the following glucose control targets: for frail patients : HbA1c of $<8.0 \%$ and fasting plasma glucose between 6.0 and $8.0 \mathrm{mmol} / \mathrm{l}$; for non-frail and those with an absence of co-morbidities, an HbA1c of $<7.0 \%$ and fasting plasma glucose between 5.0 and $7.0 \mathrm{mmol} / 1$. Recommendations for both lipid and blood pressure targets are also given. These provide a large part of the framework needed ultimately to enhance diabetes care in older people.

Striving for clinically and cost-effective diabetes care for older people is a worthwhile goal. It requires a consistent and sustained approach to define the influence of age-related factors, the presence of unique characteristics, and the need for varying models of care. The recent recognition that aiming for effective glucose control with even lower targets may not always be beneficial may have special implications for older people. The lack of cardiovascular outcome benefit in three recent large randomised controlled trials (ACCORD (2), ADVANCE (3), and VADT (4)) despite HbA1c levels of 6.4\%, 
$6.4 \%$, and $6.9 \%$, respectively in the 'intense' arms has questioned what levels are needed. In the ACCORD study (1), there was an observed increased mortality in the intensive arm and the study was terminated early. Another twist to this story also comes from the longer term results of the UK Prospective Diabetes Study which has shown evidence of a sustained benefit in microvascular outcomes and emergence of cardiovascular benefit even though there was an early loss of glycaemic differences in the study (5).

Whilst further studies are required to elucidate risk versus benefit ratios for glucose lowering (by how much, by what method, and at what stage of the disease?) in all adults with type 2 diabetes, these observations might provide some justification for a continued focus on enhancing blood pressure lowering and lipid lowering strategies where often more tangible and consistent benefits are realised.

\section{References}

1. Bourdel-Marchasson I, Doucet J, Bauduceau B, Berrut G, Blicklé J-F, Brocker P, Constans T, Fagot-Campagna A, Kaloustian E, Lassmann-Vague V, Lecomte P, Simon D, Tessier D, Verny C, Vischer UM, for the ALFEDIAM/SFGG Frenchspeaking group for study of diabetes in the elderly. Key Priorities in Managing Glucose Control in Older with Diabetes. J Nutr Health Aging. 2009; 13(8):685-791.

2. Action to Control Cardiovascular Risk in Diabetes Study Group, Gerstein HC, Miller ME, Byington RP, Goff DC Jr, Bigger JT, Buse JB, Cushman WC, Genuth S, IsmailBeigi F, Grimm RH Jr, Probstfield JL, Simons-Morton DG, Friedewald WT. Effects of intensive glucose lowering in type 2 diabetes. New Eng J Med 2008; 358:2545-59

3. ADVANCE Collaborative Group, Patel A, MacMahon S, Chalmers J, Neal B, Billot L, Woodward M, Marre M, Cooper M, Glasziou P, Grobbee D, Hamet P, Harrap S, Heller S, Liu L, Mancia G, Mogensen CE, Pan C, Poulter N, Rodgers A, Williams B, Bompoint S, de Galan BE, Joshi R, Travert F. Intensive blood glucose control and vascular outcomes in patients with type 2 diabetes. N Eng J Med 2008; 358:2560-72

4. Duckworth W, Abraira C, Moritz T, Reda D, Emanuele N, Reaven PD, Zieve FJ, Marks J, Davis SN, Hayward R, Warren SR, Goldman S, McCarren M, Vitek ME, Henderson WG, Huang GD; VADT Investigators. Glucose control and vascular complications in veterans with type 2 diabetes. N Eng J Med 2009; 360: 129-39

5. Holman RR, Paul SK, Bethel MA, Matthews DR, Neil HA. 10-year follow-up of intensive glucose control in type 2 diabetes. N Eng J Med 2008: 359: 1577-89 